\title{
EDUCAÇÃO AMBIENTAL NA CONSCIENTIZAÇÃO E PRESERVAÇÃO DO MEIO AMBIENTE: UNIDADE ESCOLAR ZEZITA SAMPAIO, BURITI DOS LOPES, PI
}

\author{
Julysse Neuma Damasceno Gomes ${ }^{1}$, Leilson Alves dos Santos $^{2}$ e Aline Aparecida ${ }^{3}$
}

\begin{abstract}
RESUMO
Este trabalho apresenta a relevância de sensibilizar os alunos, do ensino fundamental II, para que possam conscientizar-se da importância de preservar e conservar o meio ambiente. O trabalho foi desenvolvido na Unidade Escolar Zezita Sampaio que oferece ensino fundamental do $6^{\circ}$ ao $9^{\circ}$ ano, na cidade de Buriti dos Lopes- PI. Objetivou reconhecer a importância da preservação e conservação do meio ambiente e investigar como as ações dos educandos interferem nas alterações do meio ambiente. Os resultados foram obtidos pela aplicação de dois questionários semiestruturados e intercalados por atividades diferenciadas com os alunos. Foi possível concluir que os alunos possuem conhecimentos acerca do tema meio ambiente, reconhecem-se como parte integrante do meio ambiente e agente transformador do meio e com as aulas diferenciadas os temas são facilmente assimilados pelos alunos. Pois estas sensibilizaram os alunos a serem mais participativos em ações de preservação e conservação do meio ambiente.
\end{abstract}

Palavras-chave: Meio Ambiente. Sensibilização. Educação Ambiental. Práticas Pedagógicas.

\begin{abstract}
This paper presents the relevance of sensitizing the students of Elementary School, so that they can become aware of the importance of preserving and conserving the environment. The research was developed at Zezita Sampaio School Unit, which offers Elementary School from the 6th to the 9th year, in the Buriti dos Lopes City, Piauí State, Brazil. It aimed to recognize the importance of preservation and conservation of the environment and to investigate how the actions of the students interfere in the alterations of the environment. The results were obtained through the application of two semi-structured questionnaires and conducting school activities with the students. It was possible to conclude that the students have knowledge about the environment theme, they recognize themselves as an integral part of the environment and

\footnotetext{
Bióloga, especialista em Gestão e Educação Ambiental - UAB/UESPI. jhulynema@hotmail.com

${ }^{2}$ Geógrafo docente, especialista em Gestão Ambiental. Mestre em Análise e Modelagem de Sistemas Ambientais - IGC/UFMG. leylson.santos@gmail.com

3 Química docente, Mestre em Meio Ambiente e Doutoranda em Química - UFPI. allinneaparecida@hotmail.com
} 


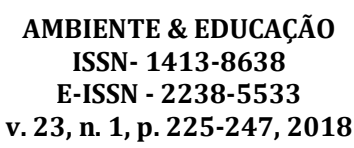

transforming agent of the environment and with the differentiated classes, the subjects are easily assimilated by the students. Because these encourage the students to be more participative in actions of preservation and conservation of the environment.

Keywords: Environmental. Awareness. Environmental Education. Pedagogical Practices

\section{Introdução}

A sociedade encontra na educação ambiental subsidio para melhorar a qualidade de vida e do ambiente, uma vez que a sua prática além de ser um processo participativo do educador e dos aprendizes é também uma forma de amor para com a vida e a natureza (CHARBAJE et. al., 2013). Neste sentido, os educadores devem auxiliar os educandos na formação de uma consciência ecológica, pois todos precisam tomar consciência de que o futuro humano está interligado ao meio ambiente, fonte de todos os recursos que subsidiam a vivência da humanidade e, para que isso ocorra é necessário praticar ações ecologicamente corretas.

Tendo em vista a escassez de projetos voltados a conservação do ambiente natural na cidade de Buriti dos Lopes, este trabalho foi desenvolvido com o objetivo de despertar a conscientização dos sujeitos envolvidos para melhorar as condições do meio ambiente e, consequentemente auxiliar na preservação de áreas naturais. Respaldado na Constituição Federal/88, que garante em seu artigo 225 o direito ao meio ambiente ecologicamente equilibrado, bem de uso comum do povo e essencial à sadia qualidade de vida, onde o Poder Público e à coletividade o devem defendê-lo e preservá-lo para as presentes e futuras gerações".

O presente trabalho objetivou, ainda, reconhecer a importância da preservação e conservação do meio ambiente como fator de sobrevivência e investigar junto aos alunos de uma escola estadual de ensino fundamental de $6^{\circ}$ ao 9 ano como as ações dos educandos interferem nas alterações ambientais.

A escola foi informada e esclarecida sobre os objetivos do projeto, sendo que durante a coleta de dados foi garantido, aos participantes, sigilo absoluto sobre as informações oferecidas, sem qualquer risco ou prejuízo as suas 
atividades junto ao colégio, bem como o direito de desistir de participar da pesquisa a qualquer momento. Os dados obtidos foram utilizados em caráter estritamente científico, visando contribuir na formação e difusão do conhecimento. Os pais e/ou responsáveis dos alunos também foram comunicados e autorizaram a participação dos mesmos na realização das atividades, bem como a divulgação de imagens.

O trabalho foi dividido em aplicação de questionários e desenvolvimento de atividades diferenciadas para sensibilizar os alunos a respeito da importância de cuidar do meio ambiente. Percebeu-se que os alunos possuem conhecimentos sobre meio ambiente, pois se reconhecem como agentes responsáveis pela preservação e conservação ambiental. Dessa maneira, as aulas com práticas pedagógicas diferenciadas são importantes e eficientes na sensibilização e desenvolvimentos de uma consciência ecológica nos educandos.

\section{Referencial teórico}

Meio Ambiente: conceito e discussões

Meio ambiente é tudo o que nos rodeia, ou seja, é a interação entre os elementos naturais e antrópicos, formado por fatores bióticos e abióticos que compõem um determinado ecossistema. Em sentido denotativo e, expresso por Ramos (2011), é o conjunto de circunstâncias ou de condições que cercam um ser vivo e que influenciam o seu desenvolvimento e as suas atividades. Assim, é possível notar que o desenvolvimento do homem está atrelado as suas práticas ambientais. Porém, em alguns casos essa parte tão importante e fundamental é negligenciada e muitos não se preocupam em alcançar o desenvolvimento sem prejudicar o meio ambiente.

Toaldo e Meyne (2013) destacam que o meio ambiente é direito de todos na forma pela qual deve ser desfrutado sem ser destruído, pois os recursos naturais são finitos e se usados desordenadamente serão extintos. É cada vez mais frequente nos meios de comunicação brasileiros notícias sobre degradação ambiental e desenvolvimento sustentável, tais notícias mostram 
que o meio ambiente está sendo desfrutado e destruído, o que contradiz os autores acima e fere o artigo 225 da Constituição Federal de 1988 no que se refere ao direito de todos a terem um ambiente ecologicamente equilibrado.

Jacobi (2006) declara que o quadro socioambiental característico das sociedades contemporâneas revela que a relação homem e meio ambiente está causando impactos gradativamente mais complexos. Tais impactos ambientais complexos não se limitam somente aos grandes centros industriais, pois nas cidades de menor porte também é possível perceber impactos provocados pela degradação da qualidade ambiental (GONÇALVES, 2015).

Como exemplo de degradação da qualidade ambiental local, em anos anteriores na cidade de Buriti dos Lopes existia uma área de brejo - planície alagada com vegetação de palmáceas - porém atualmente devido a exploração sem controle dessa espécie, esse ambiente encontra-se em estado elevado de degradação, uma vez que os olhos d'água secaram (nascentes) e o riacho que ali corria desapareceu e restam poucas palmeiras que são conhecidas como buriti (Mauritia flexuosa) da família Arecaceae.

É interessante tratar as questões ambientais partindo das experiências e problemas ambientais locais, pois o contato é real e as relações se concretizam pelas ações positivas e negativas oferecendo um retorno significante.

Para Guimarães e Inforsato (2012) a crise ambiental é um problema que foi considerado secundário por longos anos, mas atualmente vem ocupando lugar de destaque nas discussões. As alterações ambientais têm-se se intensificado de forma significativa e, assim surge a questão como o ser humano conseguiu em tão pouco tempo alterar os sistemas de uma maneira tão drástica, que talvez inviabilize a vida de muitas espécies - inclusive a do ser humano.

Tais ideias reforçam o pensamento de Matthes e Casteleins (2009) quando afirmam que as consequências da destruição confrontam com o próprio ser humano. E, no mundo atual o meio ambiente está sendo prejudicado pela própria população que não tem, em muitos casos, noção do quanto degradante são suas ações, muitas das vezes, decorrente da falta de informação e de educação. Vale ressaltar que essa ausência de informação pode ser atribuída 
às pessoas com poucos recursos financeiros que usam o meio ambiente como fonte de sobrevivência, no entanto não se aplica isso não se aos empresários que degradam em grandes proporções.

Jacobi (2006) esclarece que os ecossistemas continuam sentindo o impacto de padrões insustentáveis de produção e de urbanização; a base de recursos naturais continua estando sujeita as atividades sem controle do homem e os serviços ambientais estão absorvendo um volume maior de poluição. Com essa poluição cada vez maior, aumenta o risco de desastres ambientais e as suas consequências afetam também os setores econômicos e sociais. O mesmo autor acrescenta que os múltiplos riscos são elementos essenciais para entender os limites da modernidade provocada pelas atividades do homem.

Diante de inúmeros problemas ambientais que levam a extinção de recursos naturais e comprometimento do desenvolvimento da humanidade é necessário que o homem mude seus pensamentos sobre o meio ambiente. Toaldo e Meyne (2013) indicam que através de uma educação ambiental contínua as pessoas podem formar uma consciência ecológica buscando a valorização e preservação do meio ambiente.

\section{Educação Ambiental}

A Educação Ambiental compreende os processos por meio dos quais 0 indivíduo e a coletividade constroem valores sociais, conhecimentos, habilidades, atitudes e competências voltadas para a conservação do meio ambiente, bem de uso comum do povo e essencial para uma sadia qualidade de vida e sua sustentabilidade (BRASIL, 1999).

O surgimento da Educação Ambiental (E.A) formal trouxe novas percepções aos envolvidos no processo de ensino aprendizagem, uma vez que deixou de ser trabalhada apenas por naturalistas e passou a permear as instituições formais de ensino (KAWASAKI; CARVALHO, 2009). A Educação Ambiental, segundo Tavares, Martins e Guimarães (2002) citado por Franco et. al. (2012) é discutida no Brasil há poucas décadas, porém vem assumindo 
AMBIENTE \& EDUCAÇ̃̃̃O

ISSN- 1413-8638

E-ISSN - 2238-5533

v. 23, n. 1, p. $225-247,2018$

novas dimensões a cada ano, principalmente, pela urgência de reversão do quadro de deterioração ambiental em que vivemos.

No Brasil, a E. A. segundo a Lei no 9795/99 é o processo pelo qual os indivíduos coletivamente constroem valores sociais, conhecimentos, habilidades, atitudes e competências voltadas para a conservação do meio ambiente, ou seja, é bem de uso comum do povo. Nessa perspectiva, o país se destaca ao instituir a Educação Ambiental como tema transversal na Educação Nacional, orientando que essa deverá ser desenvolvida em todas as disciplinas curriculares devido sua complexidade de relações (BRASIL, 2001). Para reforçar sua aplicação nas escolas acrescentou-se o tema na Lei de Diretrizes e Bases da Educação Nacional - ํㅜ 9.394/96, art. 26, § 7º: os currículos do ensino fundamental e médio devem incluir os princípios da proteção e defesa civil e a educação ambiental de forma integrada aos conteúdos obrigatórios.

Assim, a educação ambiental em uma instituição de ensino apresentase como uma prática social voltada para diminuir e propor soluções para os problemas socioambientais (GUIMARÃES e INFORSATO (2012), apud CHARBAJE et. al., 2013). Dessa forma, efetivar a educação ambiental nas salas de aulas é indispensável para formar sujeitos conscientes de seu papel ecológico para o bem-estar da sociedade. Na busca de melhorar a relação com o meio ambiente em que vivemos e a interdependência entre todos os recursos naturais e seres vivos, a melhor estratégia é a Educação Ambiental. A esse respeito Franco et. al. (2012, p. 158) afirmam que:

a Educação Ambiental surge como auxílio para que as pessoas possam perceber o seu meio a partir de outros estímulos e visões, conscientizando-se da necessidade de preservação e da compatibilização entre a utilização dos recursos naturais e 0 desenvolvimento econômico.

É necessário sensibilizar a sociedade da importância de preservar e conservar o meio ambiente e como estratégia para atingir o maior número de cidadãos e a continuidade do processo educacional a escola é o melhor lugar. O ambiente escolar se caracteriza como um processo dinâmico e complexo, pois várias realidades sociais convivem nele o que determina um movimento contínuo de retroalimentação sociocultural. Assim, conhecer o sistema educacional é desafiador e necessário para o desenvolvimento de práticas 
educativas voltadas para a realidade socioambiental em que a escola está inserida (MAZZARINO; ROSA, 2013).

\section{Metodologia}

As ações metodológicas para alcançar os objetivos foram desenvolvidas na Unidade Escolar Zezita Sampaio em Buriti dos Lopes - PI. As atividades iniciaram em novembro e terminaram em dezembro de 2015. A pesquisa foi dividida em duas etapas intercaladas por atividades didáticas de sensibilização. Para a melhor realização da coleta de dados, utilizou-se questionários semiestruturados formado por uma série ordenada de perguntas abertas e fechadas, onde os entrevistados tinham autonomia de responder sem o auxílio do pesquisador.

$\mathrm{Na}$ primeira etapa, foi aplicado um questionário semiestruturado a 60 alunos do 6ำ ao 9 ano do turno manhã em um universo de 120 alunos, com faixa etária de 10 a 15 anos. Ressalte-se, que todos os alunos participaram das atividades didáticas de sensibilização. O questionário semiestruturado serviu para diagnosticar o nível de conhecimento dos alunos sobre educação e preservação ambiental, a fim de comparar a evolução desses ao fim do projeto.

Para sensibilizar os educandos acerca do tema, foi ministrado palestras e análises de imagens em processo de degradação ambiental local. Em outro momento, em sala de aula, os alunos produziram materiais como: cestas para descarte do lixo, cartazes, poemas, encenação e ações socioeducativas que foram expostos para a comunidade escolar. Em paralelo as atividades de sensibilização do presente trabalho, foi realizada uma aula de campo no Brejo Buritis, local que sofre com a degradação ambiental, no qual os alunos participaram sob a coordenação dos professores de geografia e artes.

Após as etapas descritas anteriormente, aplicou-se um outro questionário aos alunos para analisar a eficácia das ações desenvolvidas no âmbito da educação ambiental. A última etapa consistiu na análise das informações e tabulação de dados que foram transformados em gráficos no Excel para melhor visualização e compreensão. 
AMBIENTE \& EDUCAÇ̃̃o

ISSN- 1413-8638

E-ISSN - 2238-5533

v. 23, n. 1, p. 225-247, 2018

\section{Resultados e discussão}

Para um entendimento dos resultados do trabalho dividiu-se o primeiro questionário em três partes:

Conhecimentos prévios dos alunos sobre o que é o Meio Ambiente

$\mathrm{Na}$ primeira parte do questionário foram inseridas perguntas objetivas sobre o significado e como os alunos entendem a formação do meio ambiente. O resultado foi satisfatório, pois $98,3 \%$ dos alunos afirmaram saber 0 significado de meio ambiente e apenas 1,7\% desconhecem o significado.

Para fundamentar a resposta, em seguida eles responderam sobre como o meio ambiente é formado. A maioria, ou seja, 78,3\% afirmaram que o meio ambiente é formado por todos os seres vivos e não vivos, $20 \%$ resumiram que o meio ambiente é formado apenas por plantas e animais e 1,7\% abstiveramse. É possível perceber que os alunos possuem conhecimento sobre o significado e formação do meio ambiente, no entanto ainda enfrentam dificuldades em se reconhecerem como parte integrante do meio ambiente, apesar de 73,3\% afirmarem que fazem parte do meio ambiente, $20 \%$ fazem parte somente em alguns momentos, $5 \%$ indicaram não fazer parte do meio ambiente e 1,7\% abstiveram-se.

\section{Disciplinas que tratam da temática ambiental}

Os alunos foram indagados se durante as aulas os professores discutem sobre preservação do meio ambiente. Os resultados apontam que 48,3\% dos professores falam frequentemente da temática ambiental, 48,3\% as vezes mencionam algo sobre o meio ambiente, 3,4\% dificilmente abordam temas da preservação ambiental. É notável que os professores trabalham esta temática como tema gerador ou mesmo transversal em suas aulas, o que consiste em um progresso nos estudos ambientais, já que estamos vivenciando um processo assustador de degradação ambiental.

A questão seguinte pedia aos alunos que indicassem quais disciplinas os professores mencionavam a preservação ambiental. Como resultado, a maior parte dos alunos apontaram: Ciências, Geografia e Português, como as 
principais. Pode-se perceber que, as disciplinas citadas aparecem como as únicas responsáveis por trabalharem a temática ambiental o que não é ideal, uma vez que os Parâmetros Curriculares Nacionais (PCNs) orientam que o tema meio ambiente seja transversal, indicando que o mesmo deve ser trabalhado por todas as áreas do conhecimento e não é limitado somente a disciplinas isoladas.

A temática ambiental é complexa e requer o diálogo entre as disciplinas. Sobre isso Jacobi (2006) relata que para um processo educativo articulado e compromissado com a sustentabilidade e a participação, deve ser um processo que privilegie o diálogo e a interdependência de diferentes áreas do saber, com mudanças nas práticas educativas e que estas estejam inseridas na interface dos problemas ambientais.

Apesar da preservação ambiental ser trabalhada por poucas disciplinas, os alunos demonstraram interesse no tema quando foram questionados se gostavam das aulas sobre educação ambiental. Assim, 73\% dos alunos afirmaram que gostam das aulas que tratam do tema, e 27\% informaram que as vezes gostam da aula. O interessante do questionamento é que as opções que demonstram negação a aula não foram citadas.

Sobre a metodologia usada em sala de aula pelos professores, perguntou-se: Aulas com vídeos, palestras, produção de cartazes facilitam o entendimento sobre as questões ambientais? $E$, como resposta a maioria $88,3 \%$ confirmou que aulas com esses elementos facilitam o entendimento e somente $26,7 \%$ indicou que as vezes facilita. Dessa maneira, pode-se dizer que aulas mais dinâmicas e atrativas são importantes aliadas para 0 entendimento e despertar da consciência ambiental dos alunos (SILVA, 2012), conforme os dados da figura 1 os alunos consideram as discussões ambientais de suma importância em sala de aula. 


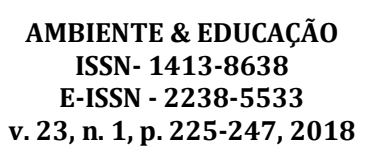

Figura 1: Demonstração do resultado que indica como os alunos consideram o tema de preservação ambiental.

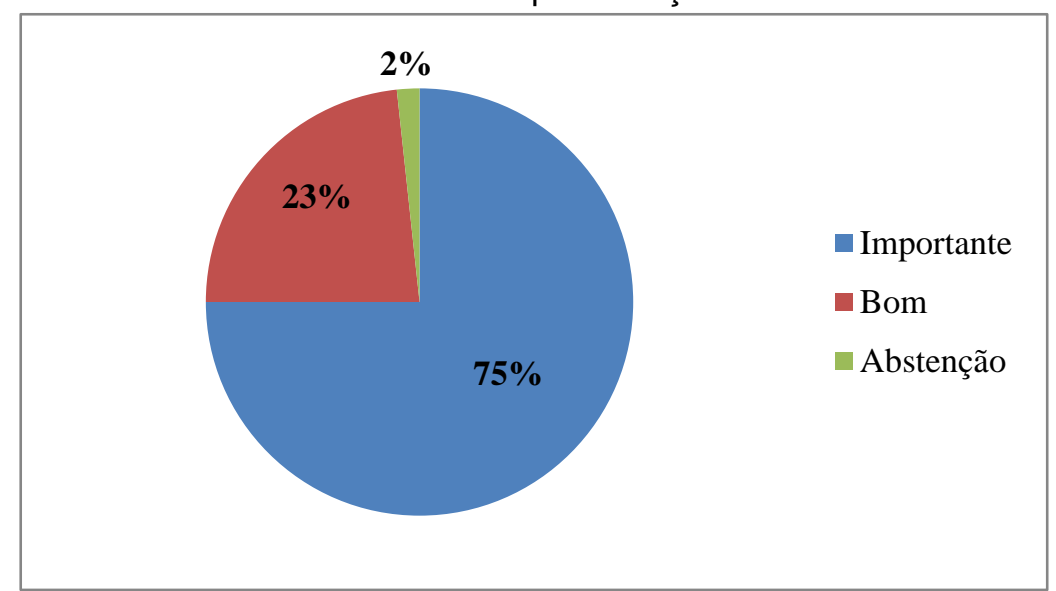

Fonte: Acervo dos autores, (2015)

\section{Atitudes dos alunos quanto a preservação do Meio Ambiente}

$\mathrm{Na}$ terceira parte do questionário a pesquisa referia-se as atitudes desenvolvidas pelos alunos quando se trata de preservar o meio ambiente e, assim analisou-se suas práticas. Perguntou-se o que é preservar? E foram dadas quatro opções com os seguintes resultados: $20 \%$ responderam que preservar é proteger e não permitir o uso dos recursos naturais; para $63,3 \%$ é usar os recursos naturais com responsabilidade; $1,7 \%$ indicou que é usar até esgotar (acabar) e 15\% acredita que preservar é usar e depois repor por um novo. A maioria dos alunos possuem consciência de que é necessário usar os recursos naturais com responsabilidade garantindo a existência dos recursos. Mas apresentam conflitos quanto ao significado dos termos preservar e conservar, eles atribuem o mesmo significado aos dois termos, assim ambos significam cuidar, de maneira simplória pode-se dizer que preservar é não usar, ou seja, deixar intocado e conservar refere-se ao uso dos recursos naturais de forma sustentável e com responsabilidade.

A questão subsequente foi sobre se cuidar do meio ambiente é um dever de todos, os alunos foram unanimes em responder que é dever de todos. Entretanto, ao serem questionados se praticam ações que ajudam a cuidar do meio ambiente, apenas 30\% afirmaram praticar frequentemente tais ações, $60 \%$ praticam as vezes, $7 \%$ dificilmente ajudam a preservar o meio ambiente 
por suas ações e 3\% não praticam ações que ajudam o meio ambiente (Figura 2).

Figura 2: Demonstração do resultado que indica a prática de ações que ajudam a preservar o meio ambiente.

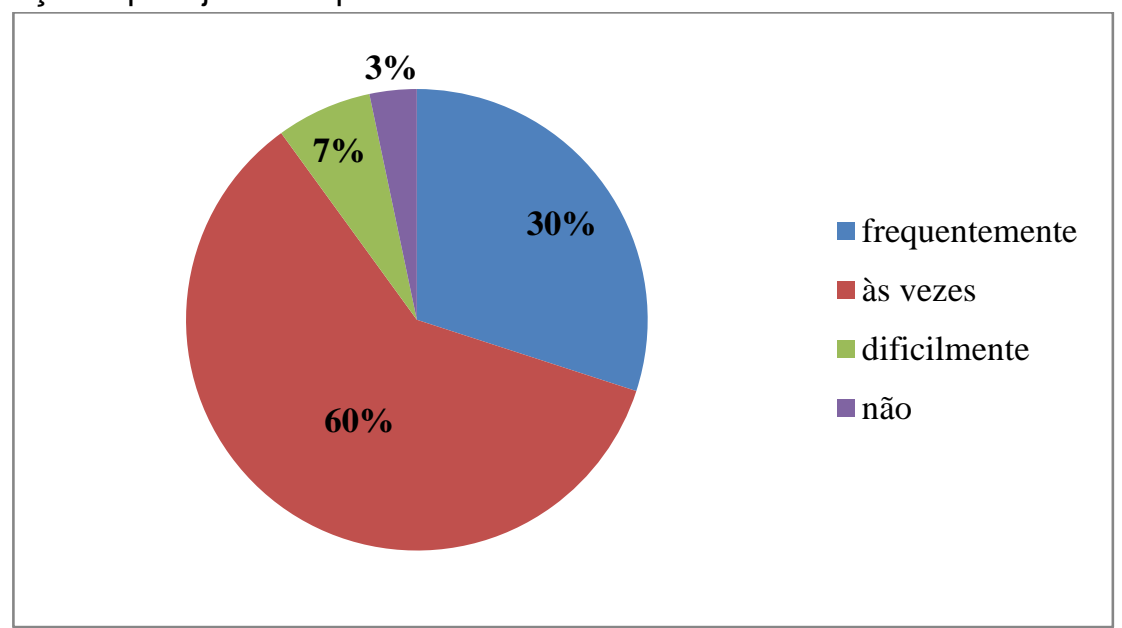

Fonte: Acervo dos autores, (2015)

Mesmo sabendo que é dever de todos cuidar do meio ambiente, ainda é pequena a parcela de alunos ativos nessas ações. Questionados sobre a extensão escola e família, perguntou-se: Você comenta em sua casa sobre a importância de cuidar do meio ambiente? E, pelos resultados obtidos, poucos alunos conversam em suas casas sobre esse assunto. Apenas $20 \%$ comentam com frequência sobre o tema, 48,3\% comentam as vezes, $23,3 \%$ dificilmente mencionam o tema em casa e $8,3 \%$ nunca falam da temática em suas casas.

Todavia, esses alunos são conscientes das ações que implicam na conservação do meio ambiente, pois 96,6\% julgaram que ações como: jogar lixo na rua, na sala de aula, queimar lixo, deixar a torneira aberta (enquanto escova os dentes) e matar os animais são ações que não preservam/conservam o meio ambiente. E, que é necessário praticar ações de preservação e conservação para melhorar a qualidade de vida. Na última questão é indagado: Você acredita que as altas temperaturas têm relação com a destruição do meio ambiente? Cerca de $78 \%$ dos alunos acreditam que sim, 15\% apresentam dúvidas a esse respeito, $2 \%$ afirmam ser difícil os fenômenos citados terem relação de causa e efeito e 5\% não acredita nessa relação. Os 


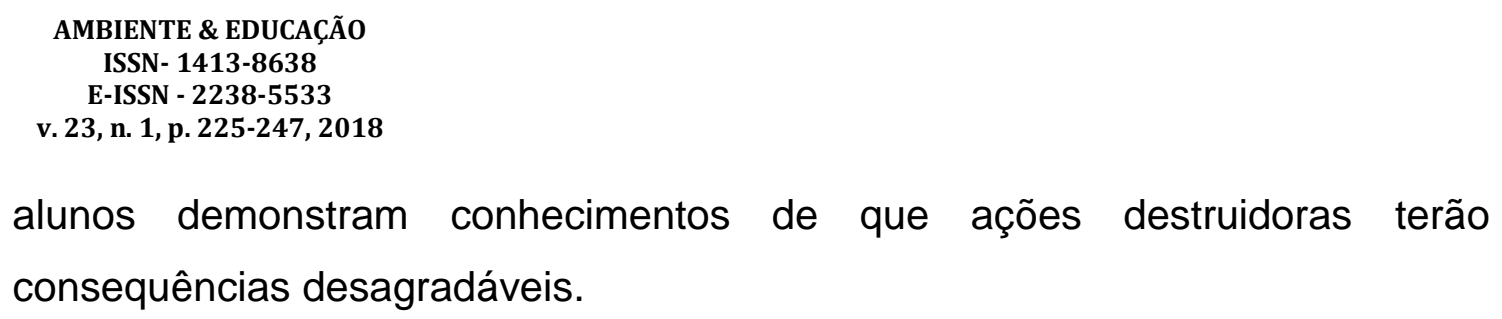

alunos demonstram conhecimentos de que ações destruidoras terão consequências desagradáveis.

\section{Desenvolvimento das atividades de intervenção}

O desenvolvimento das atividades de intervenção para a sensibilização dos alunos abordando a necessidade de preservar e conservar o meio ambiente como fator de sobrevivência ocorreu durante as aulas de ciências e foram organizados em momentos distintos:

\section{0 momento}

Explanação dos temas selecionados: Lixo, degradação ambiental e os crimes ambientais. Os temas foram selecionados devido à proximidade com a realidade dos alunos, que resultam das ações cotidianas e pelo município de Buriti dos Lopes não ter um gerenciamento correto do lixo o que contribui para a degradação do ambiente, bem como ações que são consideradas crimes ambientais as vezes cometidos sem o autor possuir consciência de que está cometendo um crime ambiental.

Durante a aula os temas foram expostos com uso de slides abordando o conceito, as ações que causam prejuízos ao meio ambiente bem como as consequências da ação antrópica e as penalidades para os atos criminosos. Foi utilizada uma linguagem de fácil entendimento para os alunos e os mesmos se mostraram bem interessados na discussão, pois fizeram muitas perguntas e citaram exemplos de ações que praticaram e deram possíveis soluções aos problemas encontrados. Os temas foram bem discutidos aproveitando os conhecimentos prévios dos alunos.

\section{0 momento}

Os alunos foram divididos em 4 equipes para o momento da confecção de cartazes e outros itens.

Equipe A - os alunos receberam imagens para colorir e estas seriam utilizadas na confecção de cartazes que tinham como tema: o lixo, quais as medidas para reduzir a produção do lixo e as consequências do descarte 
incorreto. Posteriormente foram expostos para a comunidade escolar numa amostra (Figura 3).

Figura 3: Prancha com imagens dos alunos pintando as imagens para os cartazes.
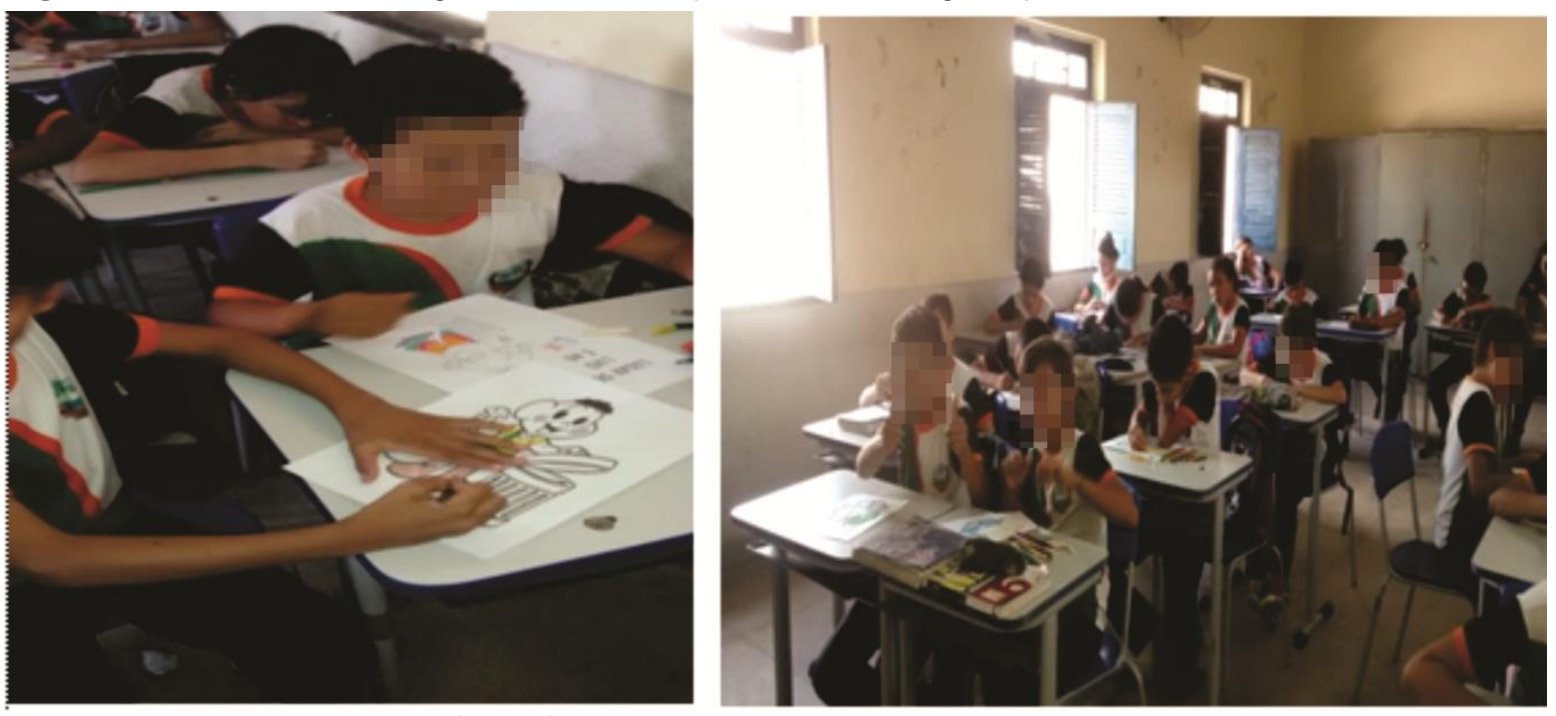

Fonte: Acervo dos autores, (2015)

Na equipe $\mathrm{B}$ os alunos ficaram responsáveis pela produção dos cestos de lixo que foram confeccionados com caixas de papelão revestidas de TNT (material sintético) de cores diferentes para representar os locais adequados para: o descarte de papel com TNT azul e plástico com TNT vermelho, confecção dos cestos coloridos serviu para iniciar os princípios da coleta seletiva principalmente na escola (Figura 4).

Figura 4: Prancha com imagens dos alunos confeccionando os cestos de lixo.
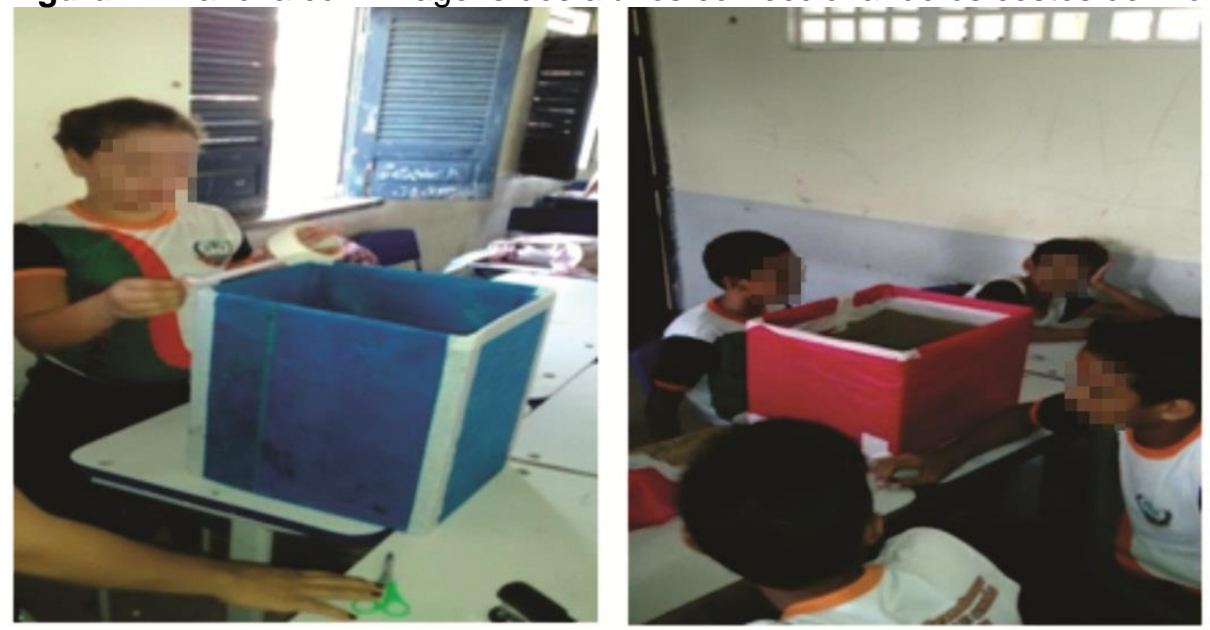

Fonte: Acervo dos autores, (2015) 
AMBIENTE \& EDUCAÇ̃̃o

ISSN- 1413-8638

E-ISSN - 2238-5533

v. 23, n. 1, p. 225-247, 2018

Os alunos da equipe $C$ focaram na degradação ambiental, por serem alunos das séries mais avançadas a atividade proposta era a produção de histórias em quadrinhos. A história deveria versar sobre um problema que degrada o meio ambiente. As histórias foram produzidas em cartolinas, papel madeira e outra em papel sulfite, a forma de organização ficou a critério dos alunos (Figura 5).

Figura 5: Prancha com imagens dos alunos produzindo as histórias em quadrinho.
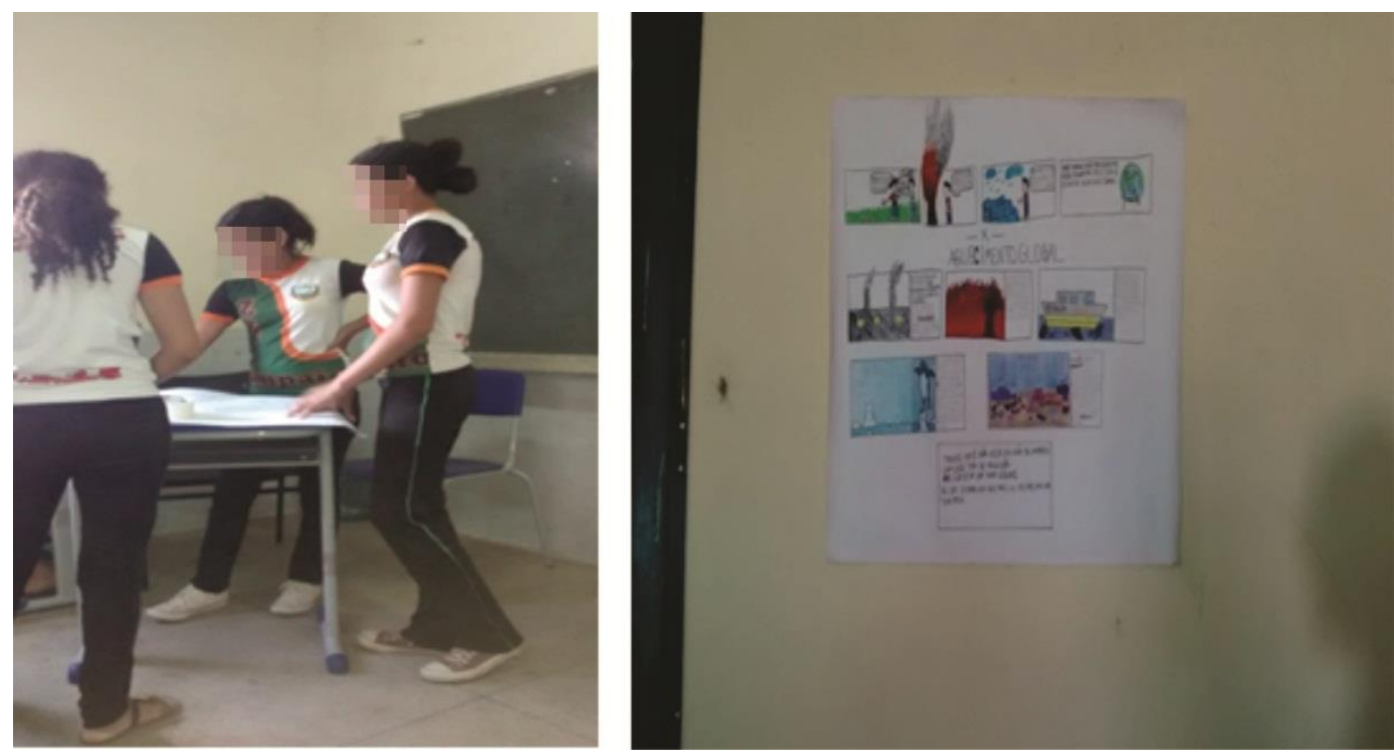

Fonte: Acervo dos autores, (2015).

O grupo de alunos da equipe $D$ encenaram pequenos atos sobre os crimes ambientais que ocorrem no município de Buriti dos Lopes, e como base utilizou-se uma cartilha de crimes ambientais divulgada e disponibilizada pelo IBAMA. Montou-se um cenário e os animais eram simbolizados por desenhos estampados nas camisas dos alunos (Figura 6). 
Figura 6: Prancha com imagens dos alunos ensaiando para a peça sobre crimes ambientais.
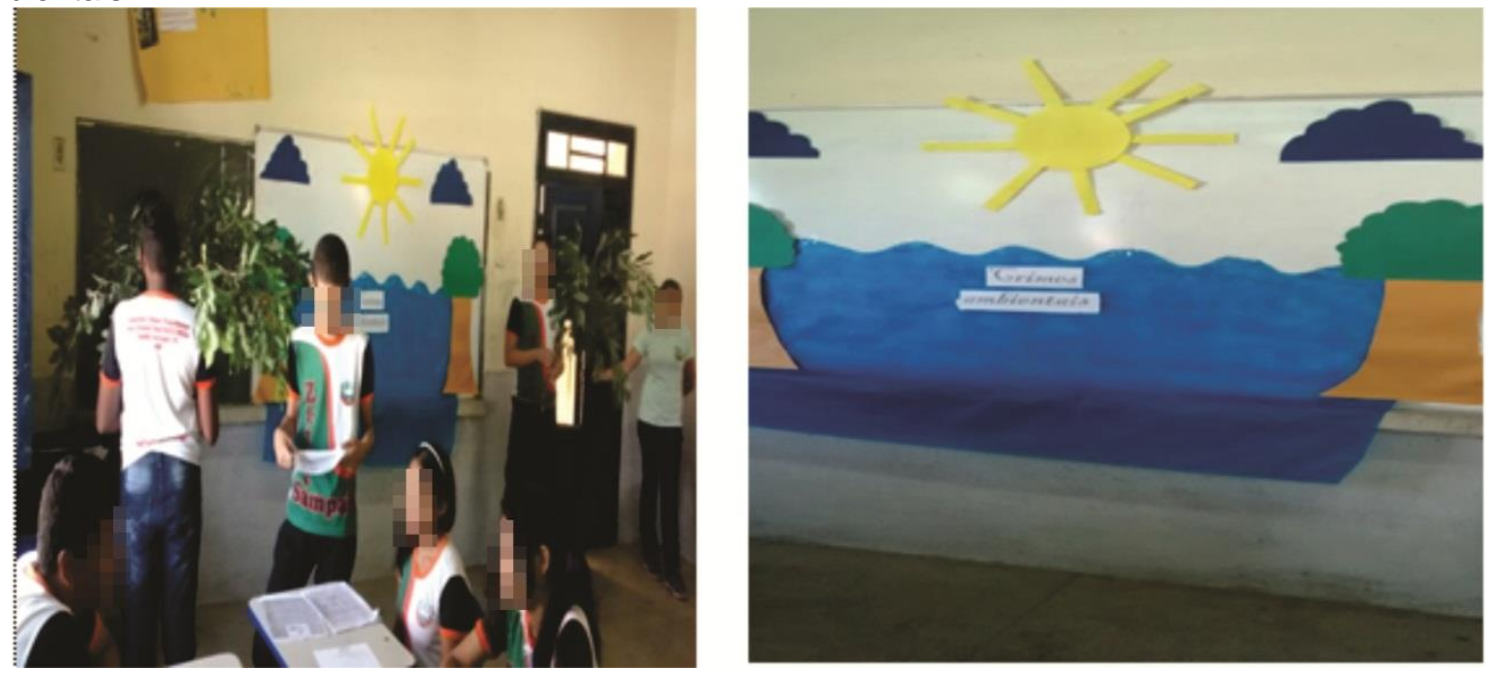

Fonte: Acervo dos autores, (2015)

Durante a confecção dos cartazes, dos cestos da coleta seletiva, da elaboração das historinhas em quadrinhos e dos ensaios da peça teatral, os alunos foram estimulados a realizarem pesquisas que enriqueceu seus conhecimentos acerca dos temas trabalhados e discutidos.

\section{3o momento:}

Nessa etapa das atividades de sensibilização, os alunos apresentaram seus trabalhos para a comunidade escolar. Os cartazes foram expostos na escola, as histórias em quadrinhos foram explanadas e os alunos da equipe D encenaram a peça teatral para toda a comunidade escolar.

Foi possível notar a motivação dos alunos em participarem ativamente desse processo de (re)construção do conhecimento, pois são temas bem comuns e que interferem em nosso dia a dia. Durante as atividades de sensibilização, observou-se que os alunos começavam a cobrar uns dos outros por atitudes responsáveis em relação ao meio ambiente e a questão do lixo produzido na sala de aula melhorou. As salas ficaram menos sujas, pois evitavam jogar papéis no chão e retornavam de suas casas com novas histórias que conversavam com os pais, invertendo os dados a respeito de uma pergunta do primeiro questionário em que poucos falavam em casa da importância de cuidar do meio ambiente (Figura 7). 
AMBIENTE \& EDUCAÇ̃̃o

ISSN- 1413-8638

E-ISSN - 2238-5533

v. 23, n. 1, p. 225-247, 2018

Figuras 7: Prancha com imagens dos alunos expondo suas produções para a comunidade escolar.
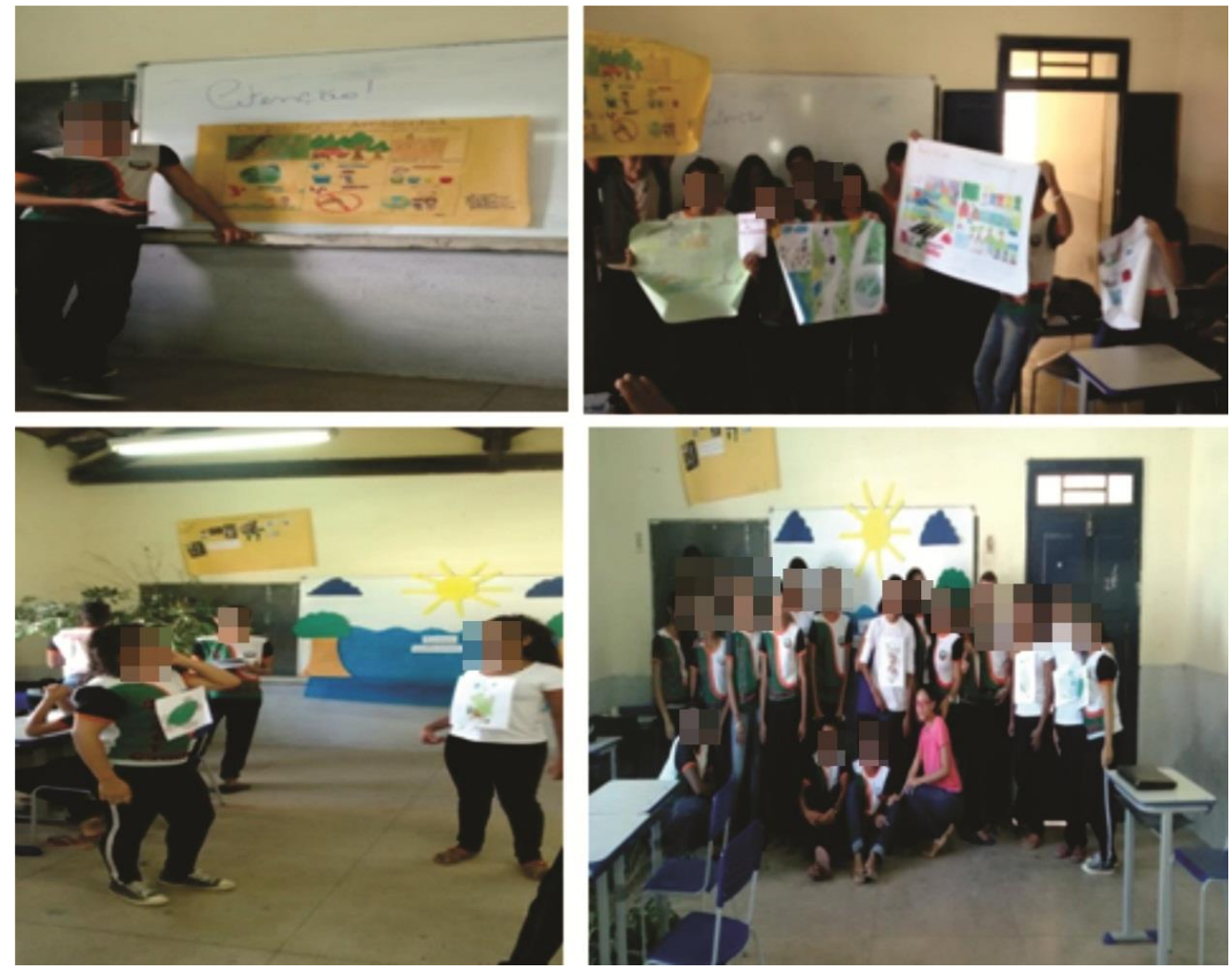

Fonte: Acervo dos autores, (2015)

Aplicação do questionário após a realização das atividades de intervenção

Para analisar a importância das atividades na sensibilização para preservação e conservação do meio ambiente aplicou-se um segundo questionário a fim de fazer uma assimilação de antes e após as atividades de intervenção. Para facilitar o entendimento, os resultados foram divididos em três partes similares a discussão do primeiro questionário:

\section{Entendimento sobre Meio Ambiente}

$\mathrm{Na}$ primeira parte pediu-se a definição de meio ambiente. As respostas do segundo questionário foram de encontro com as respostas do primeiro questionário, no qual a maioria afirma saber o significado de meio ambiente. De forma geral, os alunos definiram o meio ambiente como o local em que vivem com os seres vivos e não vivos e que é preciso cuidar. Corroboram ainda com os pensamentos de Toaldo e Meyne (2013) que afirmam que o meio ambiente 
é formado pela água, pelo ar, pelo solo, pela energia solar, e pelos seres vivos como a fauna e flora. Abaixo algumas respostas dos alunos ao questionamento.

"Florestas, animais, rios, que devem ser cuidados."

"Local em que vivemos e que temos que cuidar"

"Tudo em volta, que vem da natureza"

"Lugar que precisamos cuidar para garantir o futuro"

Em relação a pergunta: Você se considera parte do meio ambiente? Notou-se uma melhora, pois teve aumento em relação aos que se consideram parte do meio ambiente, conforme pode ser observado na figura 8.

Figura 8: Demonstração do resultado que indica a quantidade de aluno que se consideram parte do meio ambiente

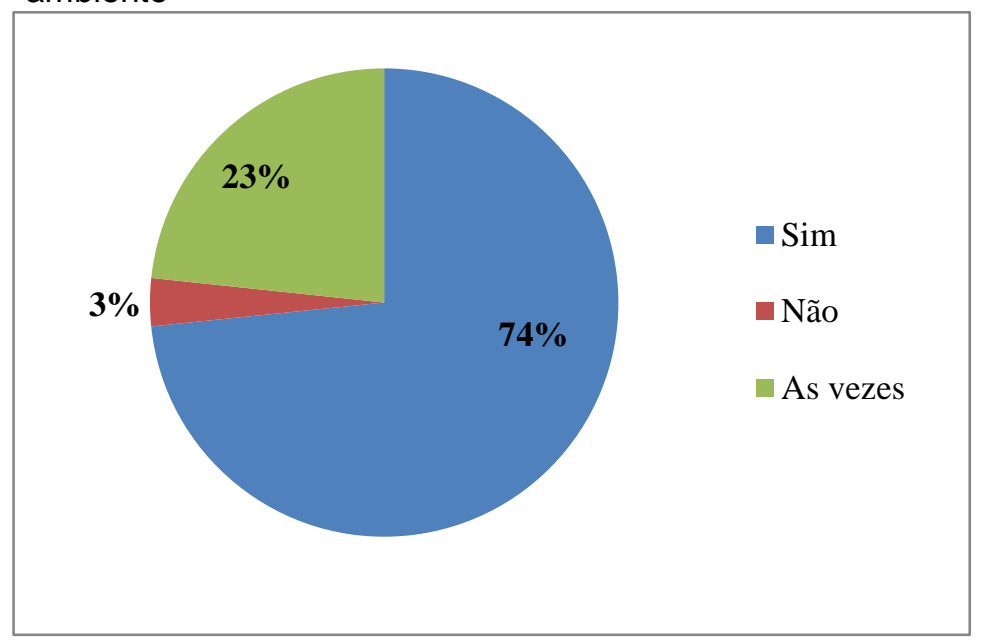

Fonte: Acervo dos autores, (2015)

Avaliação das aulas/atividades sobre as aulas e os temas trabalhados

Os resultados que seguem em análise relevam a capacidade de sensibilização dos educandos, pois as metodologias das práticas educacionais são fundamentais na formação do pensamento dos alunos, uma vez que contribui para a formação cognitiva, social e moral do sujeito. A conscientização dos educandos é o primeiro passo para formar cidadãos ecológicos atuantes, sendo que irão agir de forma racional repensando suas ações. 
AMBIENTE \& EDUCAÇ̃̃̃O

ISSN- 1413-8638

E-ISSN - 2238-5533

v. 23 , n. 1, p. $225-247,2018$

Os alunos foram questionados sobre como julgaram as aulas que abordaram sobre o lixo, degradação ambiental e preservação ambiental. $O$ resultado comprova que os temas são oportunos para serem trabalhados e que as aulas diferenciadas são importantes e despertam a curiosidade dos alunos diante de dúvidas e questionamentos (Figura 9).

Figura 9: Demonstração do resultado sobre a avaliação das aulas sobre: lixo, degradação ambiental e preservação ambiental.

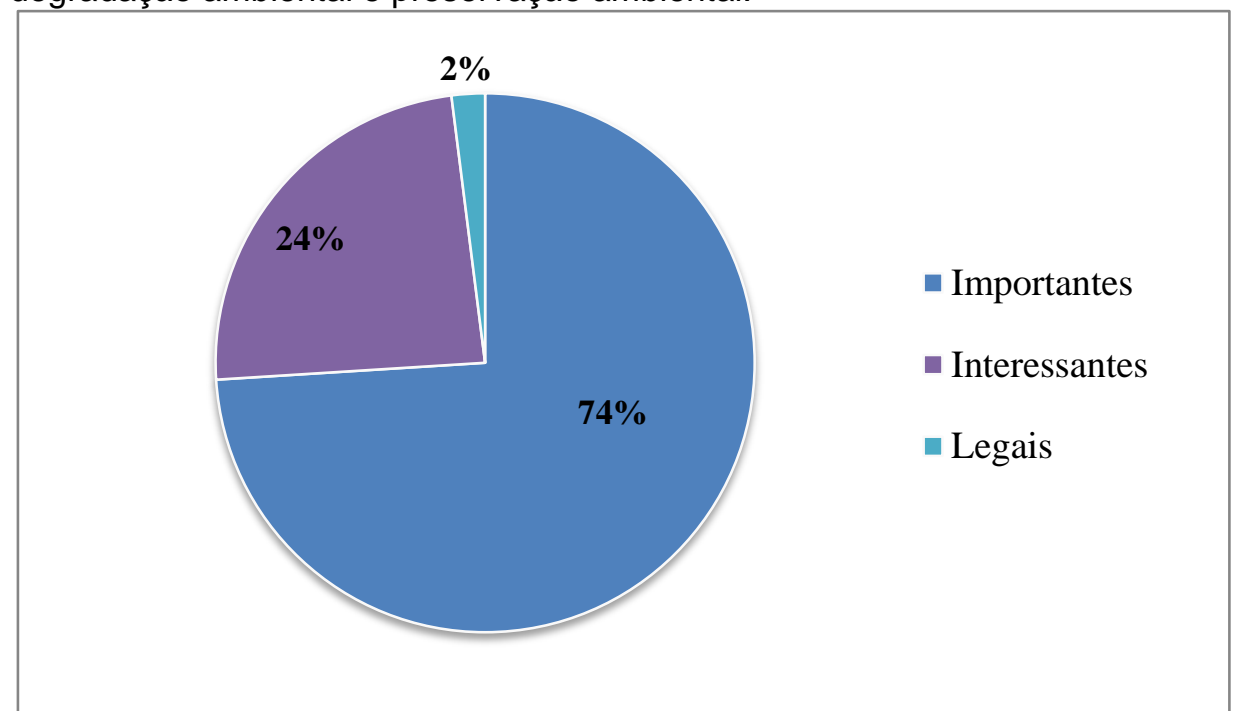

Fonte: Acervo dos autores, (2015)

Dentre os temas geradores citados acima, vários subtemas foram discutidos, uma vez que o meio ambiente é uma teia de conteúdo todos os fatores ambientais se interligam em algum momento. $E$, ao serem indagados sobre qual tema mais chamou a atenção durante as aulas citaram alguns, a saber: $46,6 \%$ dos alunos citaram o lixo, seguido de degradação e preservação ambiental, cada tema com 18,3\%, meio ambiente e crimes ambientais representaram $5 \%$ cada e plantas e animais com 1,6\%. A variedade de subtemas foi reconhecida pela atenção e interesse dos alunos durante as atividades. Destaca-se, também, que os alunos participaram ativamente dos momentos propostos comprovado com a pergunta da sequência, onde 97\% afirmam que com as aulas diferenciadas ficou mais fácil entender a importância de preservar o meio ambiente.

Ao serem perguntados sobre as metodologias aplicadas nas aulas diferenciadas, os alunos responderam que a melhor metodologia é quando os 
alunos participam das aulas por meio da observação e compreensão de imagens, produção e apresentação de cartazes, pois é quando conseguem expressar o conhecimento e interagir com o professor. Como complemento do questionamento foi perguntado se após as aulas os alunos tinham mudado a ideia sobre cuidar do meio ambiente. O resultado foi muito satisfatório, todos afirmaram que não tinham o mesmo pensamento de antes e que haviam mudado suas ideias sobre como cuidar do meio ambiente. $O$ que demonstra que foram sensibilizados pelas metodologias aplicadas.

Atitudes dos alunos quanto a preservação do meio ambiente

Com o intuito de demonstrar que os objetivos foram alcançados este item mostra os resultados sobre as ações dos educandos que interferem nas alterações do meio ambiente e suas contribuições para a preservação e conservação do mesmo.

Iniciamos com o questionamento: Depois das aulas com temas ambientais você comentou em sua casa sobre a importância de cuidar do meio ambiente? Constatou-se que os alunos já mudaram suas ações, pois o número de alunos que falam com frequência em casa sobre a importância de cuidar do meio ambiente subiu de $20 \%$ para $37 \%$, reduzindo de $48,3 \%$ para $40 \%$ os que falam as vezes, aqueles que dificilmente comentam sobre o assunto caiu também de $23,3 \%$ para $8 \%$ e os que nunca falam aconteceu o contrário, aumentou de $8,3 \%$ para $15 \%$.

Sobre praticar ações que degradam o meio ambiente como jogar lixo na rua e em locais inadequados, $65 \%$ dos alunos disseram que não praticam tais ações, $25 \%$ informaram que as vezes ainda praticam as ações que prejudicam o meio ambiente, $5 \%$ realizam as ações com frequência e aproximadamente $4 \%$ informaram que dificilmente comente essas ações.

Em seguida, perguntou-se quem é o grande responsável pela destruição do meio ambiente? Por quê? E, a resposta foi lógica e simples: o homem. Porque desmata, queima, retira mais do que precisa, mata os animais e não se preocupa com a natureza. Em análise da resposta é importante destacar que 


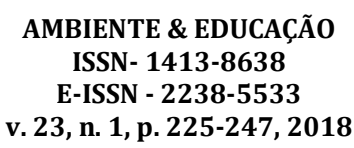

"faz-se necessário conscientizar o homem por meio do conhecimento da relação homem versus ambiente" (TOALDO; MEYNE, 2013).

Algumas respostas na íntegra:

"O ser humano, porque desmata, retira minerais sem precisar prejudicando o solo"
"Seres humanos, alguns sem noção de preservação"
"Os humanos, porque jogamos lixo em todo lugar"
"O homem, que destrói com suas atitudes" "O homem. Destruímos para suprir as necessidades sem pensar nas consequências"

Ao mesmo tempo que reconhecem que o homem é o grande responsável pela destruição do meio ambiente, os alunos também 0 responsabiliza por cuidar e evitar a degradação do meio ambiente, sendo que 93,3\% dos alunos indicaram que todas as pessoas sem definição de idade, cor e condição social são responsáveis por cuidar do meio ambiente, evitando sua degradação, enquanto $3,3 \%$ indicou que o responsável é o próprio aluno e $3,3 \%$ citaram os professores, como agentes responsáveis por cuidar do meio ambiente.

$\mathrm{E}$, sobre as aulas terem despertado o desejo de cuidar do meio ambiente, $73,3 \%$ dos alunos afirmaram que sim, já para $21,6 \%$ as aulas as vezes despertaram o desejo de cuidar do meio ambiente, 3,3\% indicaram que será difícil despertar o desejo de cuidar do meio ambiente e 1,6\% afirmou que a aula não despertou o desejo de cuidar do meio ambiente. É necessário que este trabalho seja contínuo para motivar mais alunos a participarem de forma ativa da preservação e conservação ambiental.

Toaldo e Meyne (2013), afirmam que quando se objetiva a formação da personalidade em relação ao meio ambiente ecologicamente equilibrado é preciso que seja realizado um trabalho permanente com essas pessoas. Os autores afirmam ainda que para prevenir de maneira adequada é necessário conscientizar e educar, sendo a educação ambiental um forte mecanismo nesse processo.

E finalizando o questionário, foi perguntado se após conhecerem a importância de preservar e conservar o meio ambiente, o aluno se sentia capaz de repassar informações para que outras pessoas pudessem contribuir na manutenção do mesmo. A resposta foi satisfatória, pois $77 \%$ dos alunos alvo 
da pesquisa se consideram aptos para dar continuidade a essa tarefa, seja na escola ou na comunidade em que vivem.

\section{Conclusão}

Analisando os resultados da pesquisa e as atividades de sensibilização realizadas com os alunos do ensino fundamental do turno manhã da Unidade Escolar Zezita Sampaio na cidade de Buriti dos Lopes - PI, pode-se concluir que os alunos possuem conhecimentos acerca do tema meio ambiente e se reconhecem como parte integrante do meio ambiente e agente transformador do meio, principalmente, por considerarem o ser humano como o principal agente destruidor do meio ambiente.

Os alunos compreendem os temas ambientais com mais facilidade quando são utilizadas metodologias diferenciadas nas aulas expositivas com aulas mais dinâmicas, seja com apresentação de imagens em power point e/ou com produção de cartazes que potencializam a integração e discussões propostas em sala. Tais práticas o torna mais motivado, sensibilizado com a necessidade de cuidar da natureza e conscientes de que o futuro depende do meio ambiente equilibrado. Entretanto, é necessário que todos os professores trabalhem a temática transversalmente para garantir a formação contínua dos alunos sem deixar esse trabalho a cargo dos professores de Ciências, Geografia e Português.

Conclui-se, ainda, que a sensibilização contínua é imprescindível para a formação da consciência ecológica dos alunos. E, que devem ser sensibilizados em todas as etapas de sua formação garantindo a eficácia na preservação e conservação do meio ambiente. Sendo que a melhor metodologia é inserir os alunos ativamente no processo de ensino aprendizagem.

\section{Referências}

BRASIL. Lei no 9.795, de 27 de abril de 1999. Dispõe sobre a educação ambiental, institui a Política Nacional de Educação Ambiental e dá outras 
AMBIENTE \& EDUCAÇ̃̃o

ISSN- 1413-8638

E-ISSN - 2238-5533

v. 23, n. 1, p. 225-247, 2018

providências.

Seção

1 ,

p. $\quad 1$.

Disponível

<http://www.planalto.gov.br/ccivil_03/leis//9795.htm> em: Acesso em: 15 set. 2015

. Constituição da República Federativa Dd Brasil De 1988. Seção III.

Capitulo VI do Meio Ambiente. Disponível em: <http://www.planalto.gov.br/ccivil_03/constituicao/constituicaocompilado.htm> Acesso em: 15 set. 2015

. Ministério da Educação e do Desporto. Parâmetros Curriculares

Nacionais: meio ambiente. 3ª Ed. Brasília: MEC/SEF, 2001.

. Lei no 9.394, de 20 de dezembro de 1996. Disponível em: <http://www.planalto.gov.br/CCIVIL_03/leis/L9394.htm> Acesso em 02 set.2015

CHARBAJE, R. R.; SARAIVA, I.S.; BARROS, M.D.M. Educação Ambiental no âmbito formal de ensino: uma abordagem para a formação de cidadãos. Ambiente \& Educação. v.18 (2), p. 229-243, 2013.

FRANCO, A. R.; MORAIS, G. A. C. de; NETO, J.D.; LOPES, J.C.C.; LEUCAS, H. L. B. de; GUADALUPE, D. C.; BARROS, M. D.M de. Estudo de percepção ambiental com alunos de Escola Municipal localizada no entorno do Parque Estadual da Serra do Rola-Moça. Ambiente \& Educação. v.17 (1), p. 155175, 2012.

GONÇALVES. M. J. Legislação Ambiental. FUESPI, 2015.

GOMES, J. N. D. Educação ambiental e a formação ecológica dos alunos do 9o ano do ensino fundamental de uma escola municipal de Buriti dos Lopes. 2012, 32 p. Trabalho de Conclusão de Curso (Ciências Biológicas) UAPI/UFPI.

GUIMARÃES, S. S. M.; INFORSATO, E. do C. A percepção do professor de biologia e a sua formação: a educação ambiental em questão. Ciência \& Educação. v. 18, n. 3, p. 737-754, 2012. 
JACOBI, P. Educação ambiental e 0 desafio da sustentabilidade socioambiental. 0 mundo da saúde. São Paulo, v.30, n. 4, p. 524-531, 2006.

KAWASAKI, C. S; CARVALHO, L. M. de. Tendências da pesquisa em Educação Ambiental. Educação em Revista. Belo Horizonte, v.25, n.03, p.143-157, 2009.

MATTHES, P. M. M.; CASTELEINS, V. L. A educação ambiental: abrindo espaço para a cidadania. IX Congresso Nacional de Educação-EDUCERE e III Encontro Sul Brasileiro de Psicopedagogia. PUCPR. 26 a 29 de outubro de 2009.

MAZZARINO, J. M.; ROSA, D. C. da. Práticas Pedagógicas em Educação Ambiental: o necessário caminho da auto-formação. Ambiente \& Educação. v.18 (2), p. 121- 144, 2013.

RAMOS, R. A. (Resp.). Dicionário didático de língua portuguesa. 2.ed. São Paulo: Edições SM, 2011.

TOALDO, A. M.; MEYNE, L. S. A educação ambiental como instrumento para a concretização do desenvolvimento sustentável. I Congresso Internacional de Direito Ambiental e Ecologia Política - UFSM e III Seminário Ecologia Política e Direito na América Latina. Revista Eletrônica do Curso de Direito. UFSM. v. 8, 2013.

SILVA, D. G. A importância da educação ambiental para a sustentabilidade. 2012. 11 p. Trabalho de Conclusão de Curso (Ciências Biológicas) - FAFIPA. 